\title{
THE EFFECT OF DIGITALIS ON NODAL RHYTHM WITH RECIPROCAL BEATS
}

BY

\author{
EVAN FLETCHER AND MAUDE STEVENSON
}

From the Belfast City Hospital

When the A-V node is the dominant pace-maker of the heart, the effect of drugs on its fundamental properties can be studied, especially with reference to the duration of its refractory period and the rate of anterograde and retrograde conduction. Digitalis has been observed to precipitate reciprocal rhythm (White, 1915; Blumgart and Gargill, 1930, Case 1). Dechard and Ruskin (1943) related the concentration of digitalis in the body to the effect produced on the A-V node. They found that digitalis delays conduction in the A-V node, retrograde conduction proportionately more so than anterograde conduction, the effect increasing with the accumulation of the drug in the body, although in the initial stages of digitalization retrograde conduction was accelerated. Their recovery curves for anterograde conduction, obtained by graphically relating the $\mathrm{R}-\mathrm{P}$ and $\mathrm{P}-\mathrm{R}$ intervals, showed an apparent delay of recovery of the A-V node, being most conspicuous when retrograde conduction was much prolonged.

\section{Details of Observations}

A man, aged 45 years, weighing 8 stone ( $59 \mathrm{~kg}$.), was known to have a dominant nodal rhythm with recurrent spontaneous reciprocal beats. Full details of an experimental study of this case have already been reported (Fletcher and Stevenson, 1955). He remained resting in bed throughout the period of observation, and received no drugs likely to influence the mechanism of the heart beat, other than the experimental dose of digitalis. A control cardiogram was taken immediately before administration of $0.5 \mathrm{mg}$. digoxin (B. W. \& Co.), by mouth on a fasting stomach. No gastric upset occurred, although previous experience had revealed extreme sensitivity even to small doses of digitalis. Serial cardiograms were recorded at one, three, and six hours after the administration of the drug. Long strips of lead II were used to study the changes in the heart beat. Analysis of these records confirmed that the digitalis had a significant effect on the cardiac rhythm which was essentially similar in all the tracings. After twenty-four hours, the cardiogram resembled the control record. Representative cuttings from the control cardiogram and the cardiogram at the end of the third hour are shown in Fig. 1 and 2 respectively. Table I records the measurements of the conduction times in the electrocardiogram of Fig. 1, and Table II those of Fig. 2.

TABLE I

Conduction Times of Heart Beats in Electrocardiogram of Fig. 1

\begin{tabular}{|c|c|c|c|c|c|c|c|c|c|c|}
\hline Beat No. & 1 & 2 & 3 & 4 & 5 & 6 & 7 & 8 & 9 & 10 \\
\hline R-P in $\frac{1}{100}$ sec. . & 11 & 28 & 10 & 28 & 12 & 31 & 13 & 30 & 9 & 22 \\
\hline $\begin{array}{l}\mathrm{P}-\mathrm{R} \text { in } \frac{1}{100} \text { sec. } \\
\text { reciprocal beats }\end{array}$ & - & 39 & - & 37 & - & 30 & - & 28 & - & 35 \\
\hline
\end{tabular}




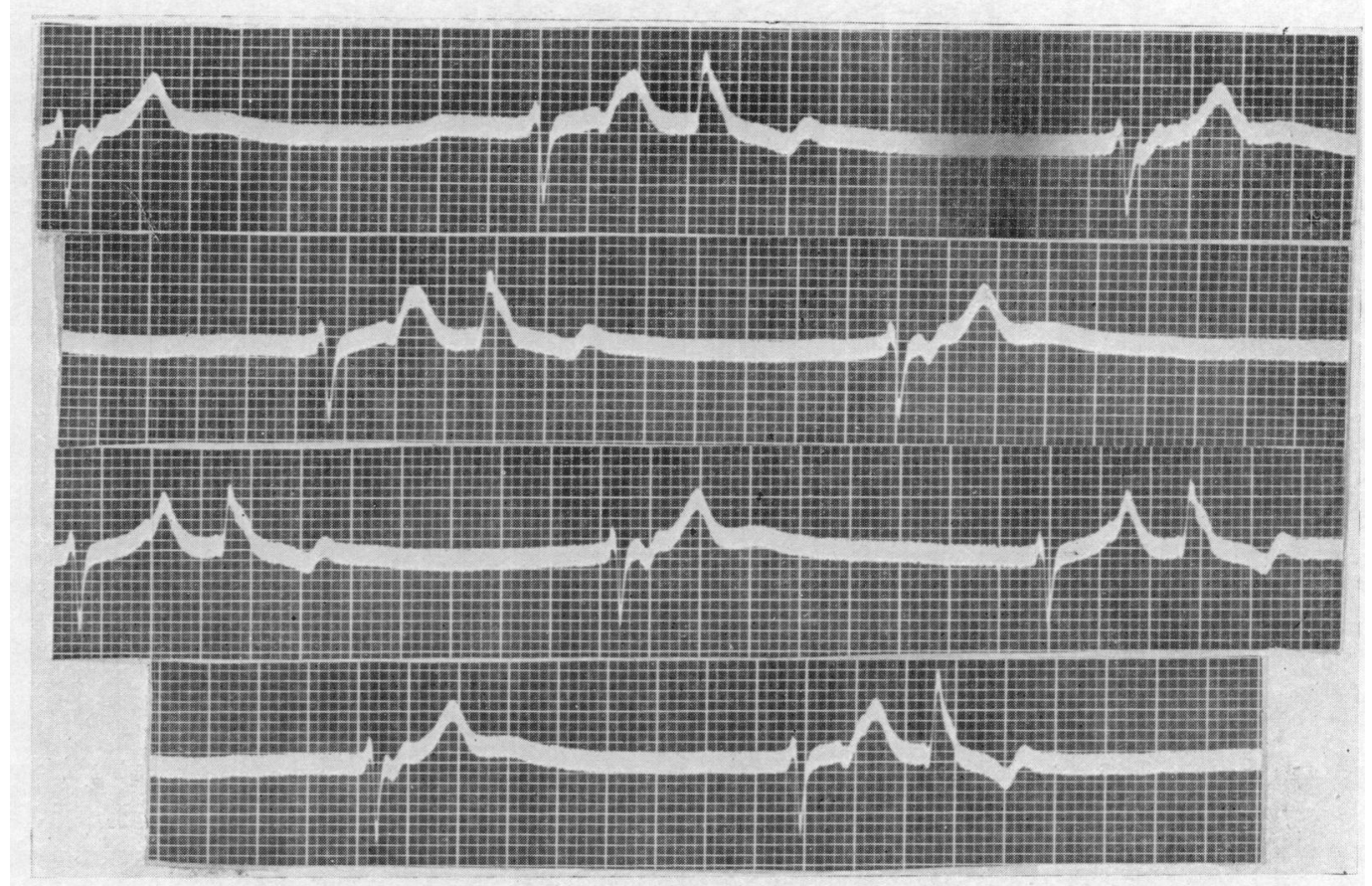

FIG. 1.-Control. Alternating reciprocal beats. Time marker 0.04 and $0.2 \mathrm{sec}$. Continuous strip lead II.

Fig. 1 demonstrates a dominant nodal rhythm with spontaneous alternating reciprocal beats, so often found in experimental tracings (Scherf-personal communication). The reciprocal beats are manifest after the longer R-P intervals (Table I). It is difficult to explain the reason for the common alternation of the R-P intervals. The rule of a fatigue and recovery mechanism may play a role by altering the time sequence of atrial and ventricular activation of post-extrasystolic beats, when nodal rhythm with pre-ventricular activation is complicated by ventricular ectopic beats without retrograde conduction (Scherf and Shookhoff, 1925).

\section{The Effect of Digitalis}

Fig. 2 reveals an increased incidence of ectopic beats. There appears to be no doubt that the ectopic beats following nodal beats No. 7, 8, 9, and 10 are due to a return mechanism. The R-P intervals in Table II are significantly prolonged compared with the control record (Table I). In fact the R-P intervals following beats No. 1, 4, and 5 in Table II are most unusually prolonged, and the beats that immediately follow them closely resemble the beats of the dominant rhythms, whereas the other ectopic beats in Fig. 2 show varying degrees of ventricular aberration which is commonly associated with reciprocal beats. Caution is necessary not to confuse A-V nodal beats

TABLE II

Conduction times of Heart Beats in Electrocardiogram of Fig. 2

\begin{tabular}{c|c|c|c|c|c|c|c|c|c|c}
\hline Beat No. & 1 & 2 & 3 & 4 & 5 & 6 & 7 & 8 & 9 & 10 \\
\hline $\mathbf{R}-\mathbf{P}$ in $\frac{1}{100}$ sec. $\cdots$ & 59 & - & 28 & 73 & 68 & - & 24 & 44 & 33 & 22 \\
\hline $\begin{array}{c}\text { P-R in } \frac{1}{100} \text { sec. } \\
\text { reciprocal beats }\end{array}$ & 16 & - & 34 & 16 & 20 & - & 40 & 16 & 28 & 39 \\
\hline
\end{tabular}




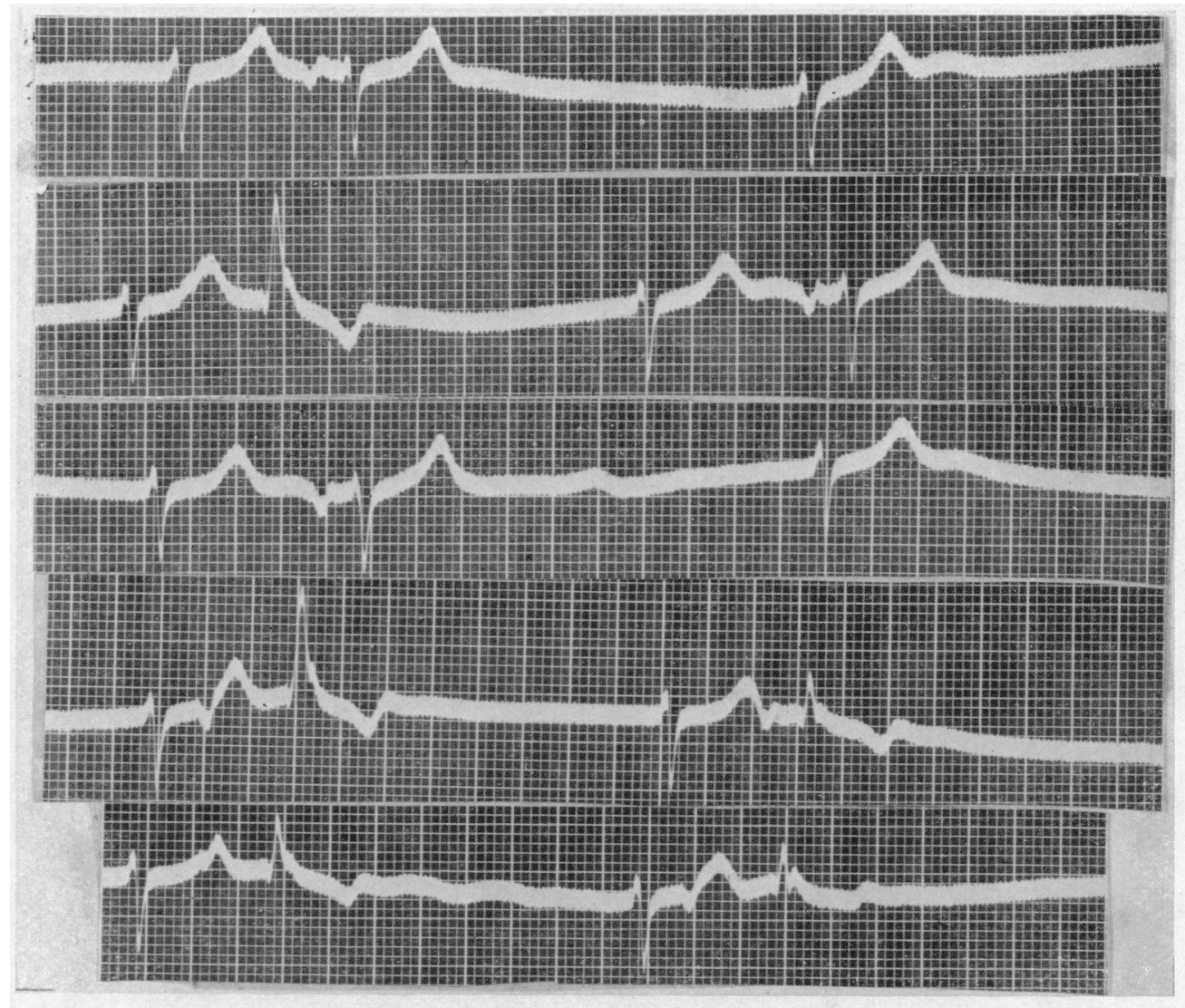

FIG. 2.-Effects of digitalis. Time marker $\mathbf{0 . 0 4}$ and $\mathbf{0 \cdot 2} \mathrm{sec}$. Continuous strip lead II.

and escaped beats with reciprocal rhythm. However, measurements of the auricular cycle lengths of Fig. 2 prove that there is a disturbance of the auricular rhythm-the fourth auricular cycle length measures $0.286 \mathrm{sec}$. and the ninth $0.204 \mathrm{sec}$. The disturbance of auricular rhythm combined with negative $P$ waves " jammed " between two ventricular complexes supports the diagnosis of reciprocal rhythm and the ectopic beats following nodal beats No. 1, 4, and 5 in Fig. 2 may well be due to a re-entry mechanism. The P-R intervals in Table II are generally shorter than in Table I, and in case of beats No. 1, 4, 5, and 8, Table II, they are within the normal range. The shortening of the period of anterograde conduction is a direct consequence of the lengthening of the period of retrograde conduction, which permits more complete recovery of the A-V node from its state of relative refractoriness following nodal discharge.

\section{Discussion}

There is no doubt that reciprocal beats in nodal rhythm are due to a re-entry mechanism (Scherf, 1941; Dechard and Ruskin, 1943). Retrograde conduction through the A-V node must be delayed to a certain critical level just greater than the absolute refractory period of the nodal tissues for a reciprocal beat to become manifest. In this case digitalis delayed retrograde conduction, so increasing the incidence of reciprocal beats. There is no evidence that digitalis had any effect on the absolute refractory period of the A-V node. Thus in beat 10 of both Fig. 1 and 2 , a reciprocal beat is manifest after an R-P interval of 0.22 sec., i.e. a fraction greater than the critical value $(0.2 \mathrm{sec}$.) for reciprocation to occur in this case (Fletcher and Stevenson, 1955). 


\section{Summary}

The effect of an experimental dose of digitalis on nodal rhythm with reciprocal beats is analysed. Digitalis significantly delayed retrograde conduction through the nodal tissues, resulting in an increase in the incidence of reciprocal beats. Anterograde A-V conduction and the absolute refractory periods of the A-V node were not influenced by digitalis under the conditions of observation.

We wish to acknowledge the helpful advice of Dr. David Scherf, New York Medical College.

\section{REFERENCES}

Blumgart, H. L., and Gargill, S. L. (1930). Amer. Heart J., 5, 424.

Dechard, D., and Ruskin, A. (1943). Tex. Rep. Biol. Med,, 1, 299.

Fletcher, E., and Stevenson, M. (1955). Brit. Heart J., 17, 285.

Scherf, D. (1941). Arch. intern. Med. 67, 372.

-, and Shookoff, C. (1915). Wein. Arch. inn. Med., 10, 97.

White, P. D. (1915). Arch. intern. Med., 16, 517. 